\title{
Electronic Article Surveillance System (EAS) \& Digital Camera Technology for Higher security
}

\author{
Surasee Prahmkaew \\ Phanakhon Rajabhat University,Thailand, surasee.p@pnru.ac.th
}

\begin{abstract}
This research aims to develop the higher security system at university's computer laboratory room. The system integrated of EAS, Arduino and ESP32-cam in box which is created for this higher security system. Arduino microcontroller that are using as preliminary stand-alone box, then we program to control this device to send the notification to laboratory administrator via line application. The EAS used RFID tag as trigger to detect person to bring the RFID which attached to the valuable things across the EAS pole. Then the Arduino detect the signal from the EAS system if one of any RFID tags across the pole mean stealing occurs, then the Arduino will order the ESP32-cam to capture thief image, next send this photo and message to the laboratory administrator via the line application. The system is well performed, reliable, and give us with impressive results.
\end{abstract}

Key words: EAS, Higher security, Digital camera.

\section{INTRODUCTION}

This system aims to prevent the theft at the University's laboratory which composed of integrated EAS technology[2], IP Camera[5], microcontroller [1] and Line application[11], together in order to reduce the burden work of lecturer and staff which is needed to stay inside the laboratory to monitor their students. The researcher has explored the previous usage of the laboratory room and found out that required a lecturer or staff to full-time monitor student to use the devices, sometimes lecture or staff has other works to operate and needed to leave the laboratory and left students to stay without staff or lecturer and perform experiment alone. Some small valuable equipment can be lost. By this circumstance, staff or lecturer will be responsible for the cost of devices lost or equipment in the laboratory, most the device has been stolen is quite small and expensive, such as WiFi antennas, mouse, cables. In addition, lecturer or staff feel despondent down for this circumstance. With this propose system, it can gain in resulting of lecturer and staff work efficiency due to not to monitor the laboratory room anymore. The propose system will alert and monitor the perpetrators via line application, by sending the captured picture who kept the valuable thing with RFID tag[3] has passed in the EAS system.

\section{TECHNOLOGY REVIEWS}

\subsection{Electronic Article Surveillance System.}

EAS or anti-theft pole is a common device which is looks like a pole at the exit gate of department store. Many people probably know that it is an anti-theft pole. But many people do not know the working principle.

There are still questions among the users on the user community, why is EAS did not make alarm sound when someone steals things?

The function of this anti-theft pole is simple, when the products passed out, EAS make alarm sound. It is sure that not all products can make the EAS make alarm sound, a product that is not very high in value is not count in EAS system. It means, the products are not protected Stolen because anti-theft devices are reasonably to protect with high price product or it can tread for difficult product to handle where it is worth to being aware of.

The EAS trick is using thing(Tag) to be install on the products in order to trigger the anti-theft performed, such as attaching a bottle strapping device. When products with these thing(Tag) pass through the anti-theft pole, there will be an alarm.

The EAS system can be classified in to type of radio frequency usage. Even through the figure of pole is looked the same. The wave form, signal strength, and tag which is important to the EAS system, including compatible devices where are differences as appropriate.

Anti-theft poles can be divided into 3 main waveforms as follows:

The Radio Frequency system is widely used in many countries; the price of EAS is not very high. The electromagnetic EM system is commonly used in libraries; This EAS system has limitations[4]. The AM system; This system started to become unpopular.

The Components The anti-theft device is divided into 3 parts as follows: 
Antenna (Alarm System)has the main function is an alarm with a sound signal. When the product is pass out and not removed tag or without payment; there are many models and materials to choose.

Detacher(Deactivator)is use to deactivate the wave form from the tag in order to prohibit the notification of antenna to operate that is calling the warning,
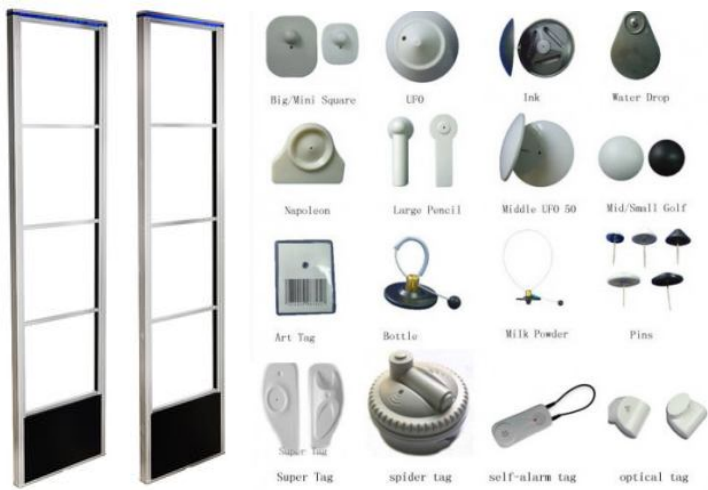

Figure 1:EAS system

The anti-theft alarm tag attached to the product comes in 2 major formats. Hard Tag when removing, it requires discs with a decoder and it can be reused, no limit on the number of times to reuse. There are a variety of forms such as plastic box sets (Hard Tag Boxes), 4-sided strap set (Guard Set), Can Locker Set, Bottle Locker Set, Anti-theft pad. Square or various shapes. Soft Tag type for attaching on products When passing through the signal cleaner, it can't be reused again. Figure 1, shows the EAS devices system.

\subsection{Digital Camera.}

The basic working principle of taking that picture by camera is simple. How light is reflected from an object and travels in a straight line through the tiny aperture of the rectangular box. Until the image of the object on the opposite side scene; the resulting image is inverted image. This is the working principle that was the origin of the creation of the pinhole camera (Obscura) in ancient times.

After that, the camera has been developed, for example, the convex lens is installed at the aperture in order to concentrate more light inside the camera, the opposite side of the lens is the location of the photosensitive material or film. Which will appear photos of the object, but the photos which is taken in the first era, the quality is not very good. But in the later eras, it is improved. User be able to adjust on the lens to achieve a clear picture then better picture on film.

A diaphragm is installed (metal petals). It likes leaves and they are stacked together to form a circular shape where it can shrink or expand to be wide, called the aperture. It has a part called the shutter, that allow the light pass through or does not. The shutter opens and closes the exposure at the specified time. All the working principles above were invented to become a camera in order to replica the principle of our human eye.

The principle operation of a digital camera[9], when it's taking pictures, the captured image will fall onto a CCD (Charge Coupled Device), a photo-receiving device that contains many photosensitive cells and these cells are responsible for converting the analog signal to digital signal by a device called an ATD (Analog to digital converter), next is the image sharpness check step, and compression process in order to reduce the space to store image. Therefore, the more cells in the CCD (Charge Coupled Device) the camera has, the better the resolution.

For a CCD (Charge Coupled Device), an electronic device that is sensitive to light, also known as an image sensor. And it is important to the resolution of the image obtained by taking pictures with a digital camera. Because the more CCD has, means the higher resolution of the resulting image. Most digital cameras have only one CCD and use a filter to filter the light. This is different from a digital video camera that has 3 CCDs to do all three colors: red, green and blue (RGB). Figure 2, shows the example of digital camera

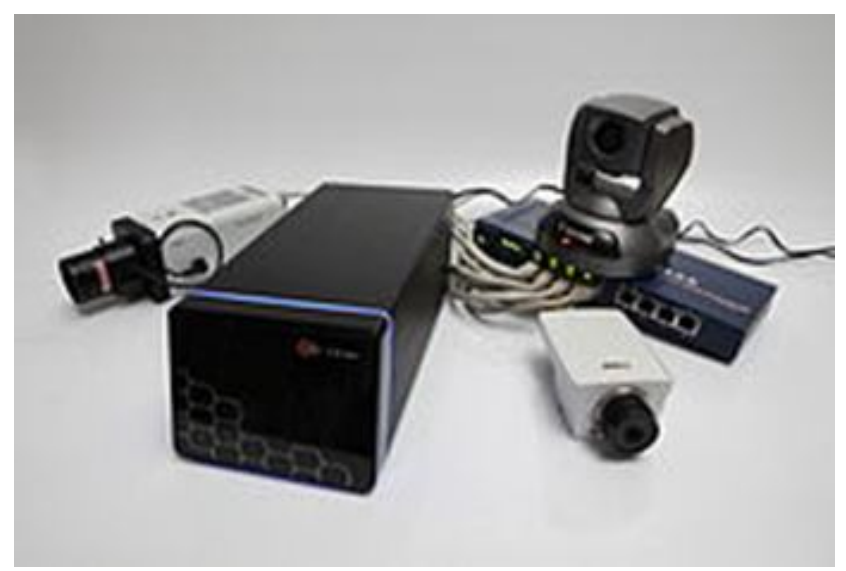

Figure 2:Digital camera

\subsection{Microcontroller Arduino UNO R3.}

The name is from the Italian language. It is an AVR microcontroller board[6] that was developed as an open source which manufacturers public information on both hardware and software. Arduino microcontroller board is designed to make it easy to use. Therefore, it is suitable for beginners to start learning programming. User could modify and developed the hardware and software as well. Arduino able to use as well as other microcontroller families [10] which is used for controlling electrical equipment by programs for controlling the work as needed. The examples of Arduino daily life applications such as automatic home lighting control, temperature measuring circuit, automatic watering control. Automatic control of opening/closing doors, coin-operated washing machines or control speed and direction Motor rotation. Figure 3, shows the UNO R3. 


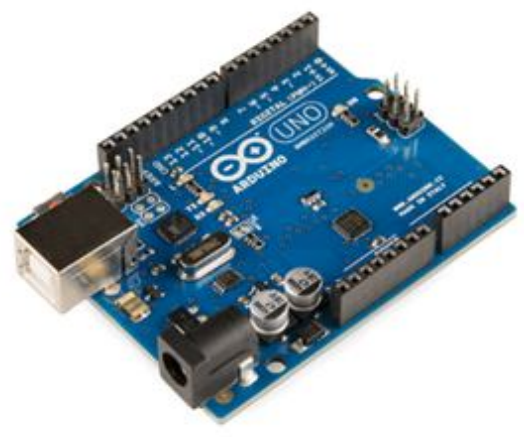

Figure 3: Arduino microcontroller

\subsection{Microcontroller ESP32-CAM}

The ESP32-CAM[7] is a full-featured microcontroller that also has an integrated video camera and microSD card socket. ESP32-CAM is a low-cost development board with WiFicamera[8]. It allows creating IP camera projects for video streaming with different resolutions. ESP32-CAM has built in PCB antenna. It's easy to use, and is perfect for IoT devices requiring a camera with advanced functions. Figure 4, shows the ESP32-CAM.

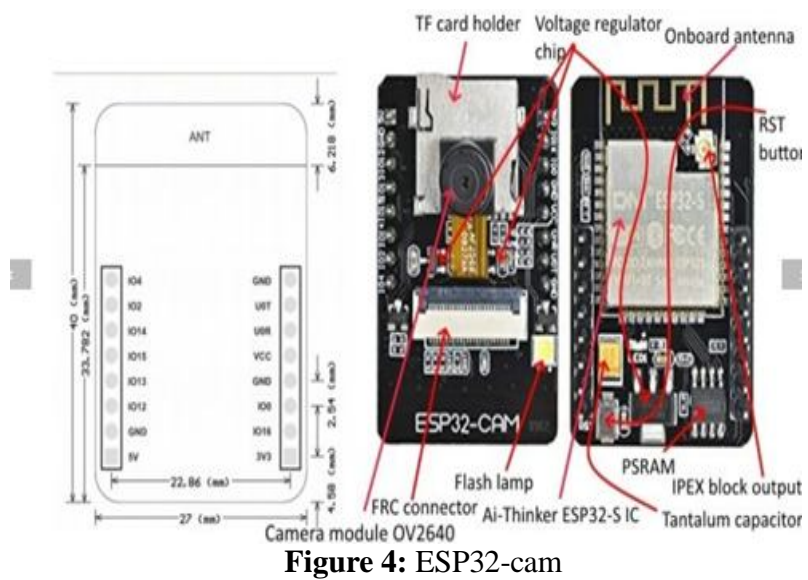

\subsection{Line Application}

Line application is most popular messenger app in Thailand, most Thai people have account on this application. It's Originally from Japan it gained huge popularity within days after its launch in early 2012 and right now it has almost 40 million active users in Thailand.

The success factor and why it is so popular in Thailand is the "stickers" - a great way to express emotions and Thais just love it and even spend money to purchase new sets of sticker albums, obviously also to show off. There are even personal profile pages with status update functions like on Facebook and Thais use that too. One cool feature of LINE is that you can do free calls as well as voice messages (which become more and more popular). Then it is easier for the laboratory administrator to obtain the notification from the propose system. Figure 5, shows the UI of Line Application.

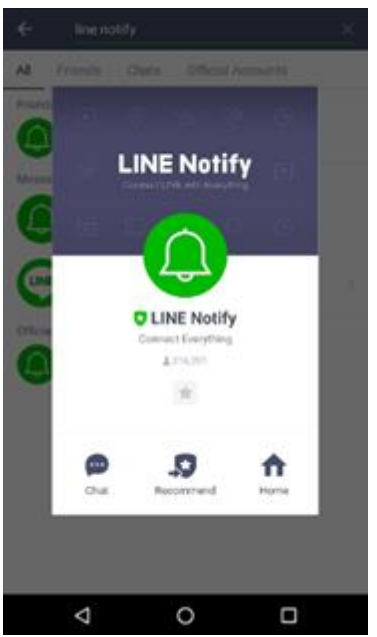

Figure 5: API Line notification

\section{SYSTEM AND MODEL DESIGN}

The proposed system composed of the EAS system which is installed at the entrance of the laboratory room as show on Figure 6., EAS is always listen to the RFID tags. If RFID tag which is attached at the valuable things has come across the EAS pole, this means that someone will stole or bring that valuable things out of the laboratory room. Such this circumstance happening, the buzzer of the EAS system will alarm, Arduino microcontroller which is used to keep track the voltage signal from the EAS's buzzer will order the digital camera (ESP32-cam) to take the photo of suspect person and send via API line notification to the laboratory administrator. For the other ways around EAS will keep track to receive the RFID tag signal and Arduino microcontroller will keep track to the EAS's buzzer voltage out and ESP32-cam will keep track the voltage which is generated out from the Arduino microcontroller. The Arduino microcontroller and ESP32 cam digital camera (ESP32-cam) had programmed in C coding to perform those functions as the system required.

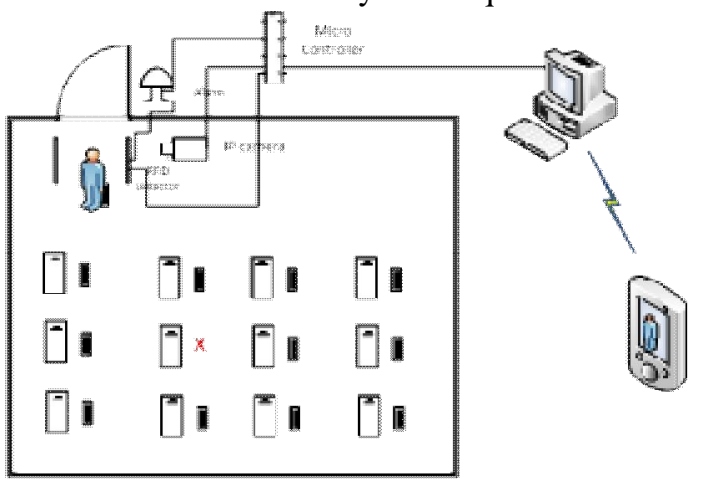

Figure 6: The proposed system layout 


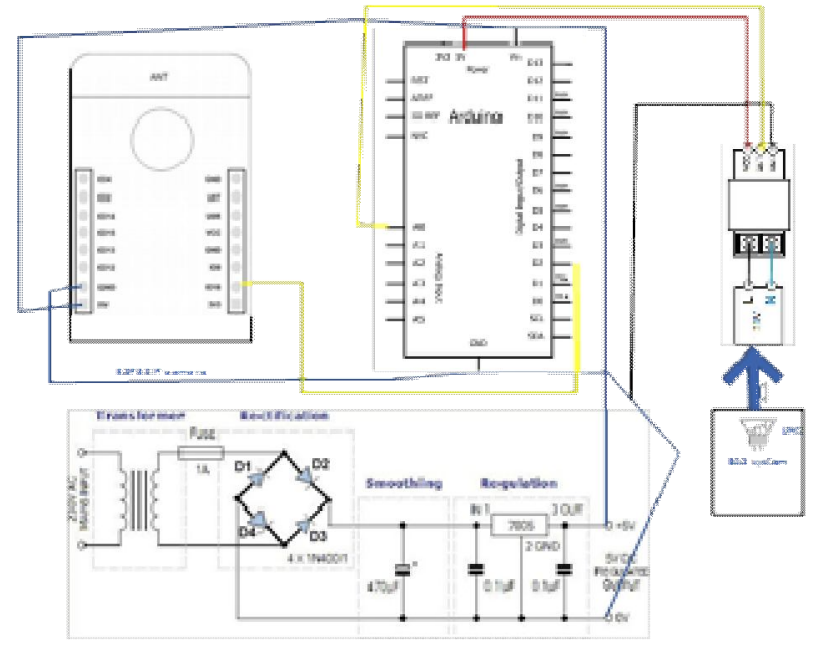

Figure 7: System Diagram

The propose system diagram is shown in Figure 7. The voltage sensor will tap the EAS buzzer voltage where its generated $24 \mathrm{Vdc}$ and $0 \mathrm{Vdc}$, Voltage sensor itself had supply with $5 \mathrm{Vdc}$ from the Arduino microcontroller and Voltage sensor signal connects to the pin $A o$ at Arduino microcontroller. The ESP32-cam had supply by the AC-DC power supply as same as Arduino microcontroller but the pin $I O_{16}$ at ESP32-cam will connect to the pin $D_{2}$ at Arduino microcontroller which acts like a trigger for ESP32-cam to capture the picture when pin $D_{2}$ at Arduino microcontroller generate the $5 \mathrm{Vdc}$ out The system is performed as the program flow chart where programmed which c language, the system work flow of the proposed system is illustrated in Figure 8 , also the hardware components is composed into the box as illustrated in Figure 9.

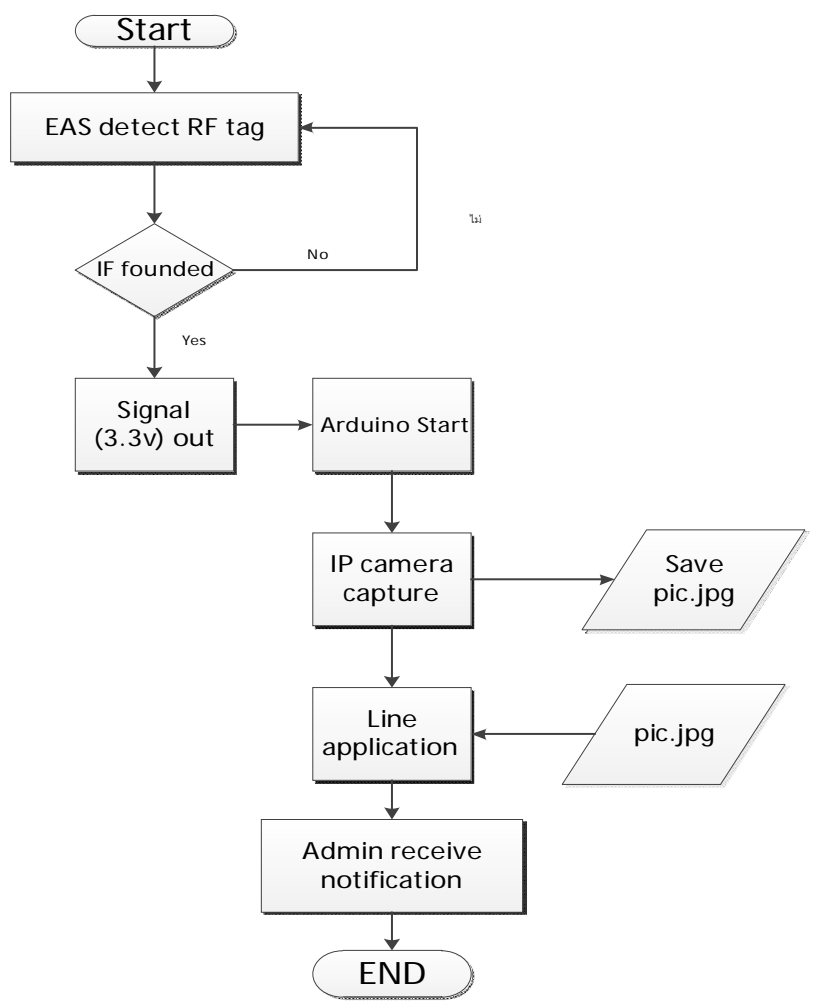

Figure 8: Program flow of the system

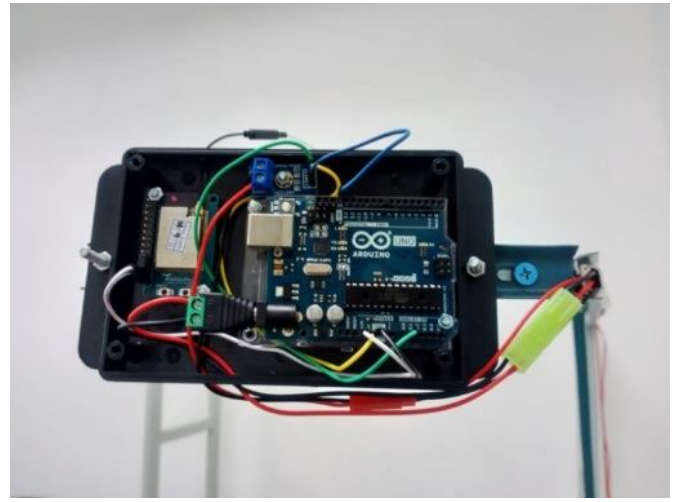

Figure 9:Proposed system box

\section{SYSTEM PERFORMANCE EVALUATION FACTORS}

The evaluation of the system performance evaluated by system reliability[12][13] and availability[14] calculations guideline plus accessibility parameter.

\subsection{Reliability}

Reliability is calculated as an exponentially decaying probability function which depends on the failure rate. Since failure rate may not remain constant over the operational lifecycle of a component, the average time-based quantities component, the average time-based quantities such as Mean time to failure (MTTF) or Mean time between failure (MTBF) can also be used to calculate Reliability. The mathematical function is specified as:

$R(t)=e^{-\lambda t}$

Failure rate is specified as:

Failurerate $(\lambda)=\frac{1}{M T B F}=\frac{1}{M T T F}$

Where MTBF is specified as:

MTBF $=\frac{\text { totalHoursofoperation }}{\text { TotalnumberofUnits }}$

$\mathrm{MTBF}=($ total Hours of operation $) /($ Total number of Units $)$

$\mathrm{MTBF}=1 / \lambda$

Where MTTF is specified as:

$$
\text { MTTF }=\frac{\text { total hours ofoperation }}{\text { Total number of failures }}
$$

\subsection{Availability}

Availability determines the instantaneous performance of a component at any given time based on time duration between its failure and recovery. Availability is calculated using the following formula: 
Surasee Prahmkaew, International Journal of Emerging Trends in Engineering Research, 9(4), April 2021, 485 - 490

$$
\operatorname{Availability} A(t)=\frac{M T B F}{M T T F+M T T R}
$$

Where Mean time to recovery (MTTR) is specified as:

$$
\text { MTTR }=\frac{\text { total hours of Maintenance }}{\text { Total number of Repairs }}
$$

$\operatorname{MTTR}=1 / \mu$

\subsection{Accessibility}

Accessibility means providing flexibility to accommodate each user's needs and preferences on this system.

\section{RESULTS AND DISCUSSION}

The proposed system has established at computer laboratory room 2742, Department of Information communications Technology, Faculty of Industrial Technology, Phanakhon Rajabhat University Thailand. since August 1st ,2020. The 3 months period of testing and time of measurement was collected as information of the system for our performance results. The measurement criteria parameters for the system efficiency will be evaluated as Reliability, Availability and Accessibility domains. The results founded as illustrated on Table 1, Figure 11., and result of Line Notification alert as shown on Figure 10.

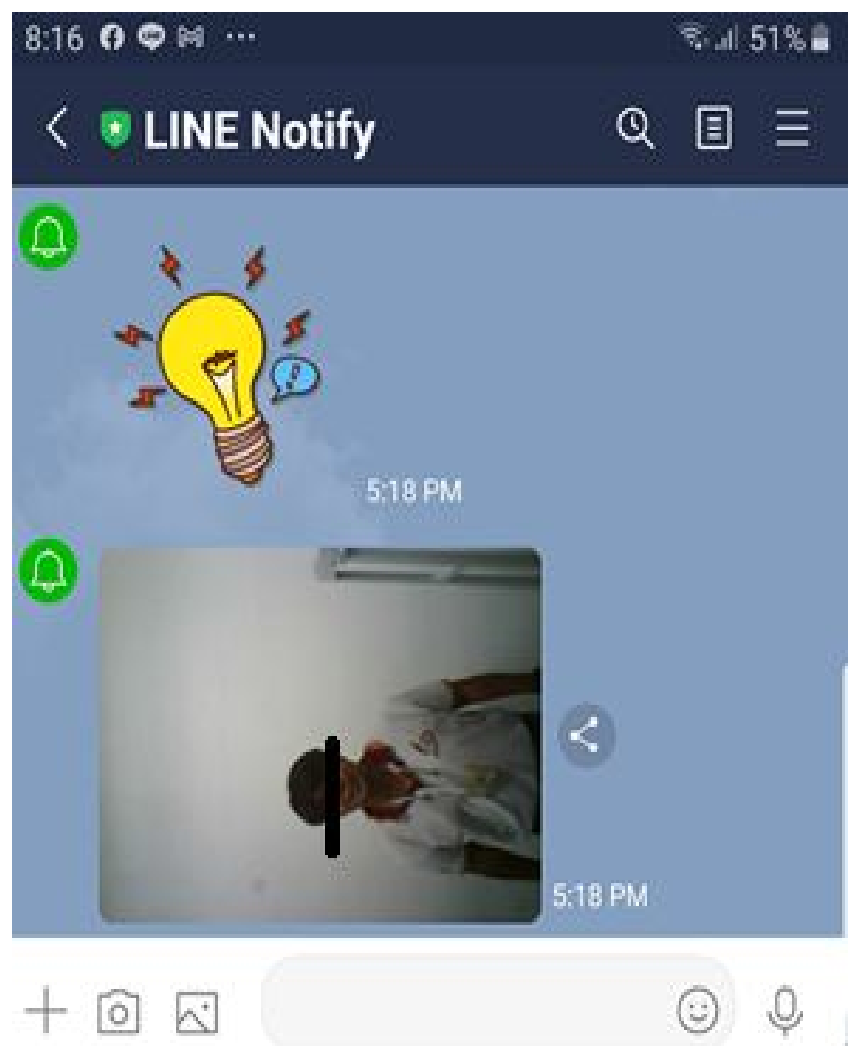

Figure 10: The picture of the suspect person from the proposed system
Table 1: The results of the proposed system

\begin{tabular}{|c|c|c|c|}
\hline \multirow{2}{*}{ Month } & \multicolumn{3}{|c|}{ Parameter Names } \\
\cline { 2 - 4 } & Reliability & Availability & Accessibility \\
\hline Aug & $100 \%$ & $100 \%$ & $100 \%$ \\
\hline Sep & $98 \%$ & $95 \%$ & $100 \%$ \\
\hline Oct & $96 \%$ & $95 \%$ & $100 \%$ \\
\hline Average & $98 \%$ & $97 \%$ & $100 \%$ \\
\hline
\end{tabular}

\section{Results of proposed system}

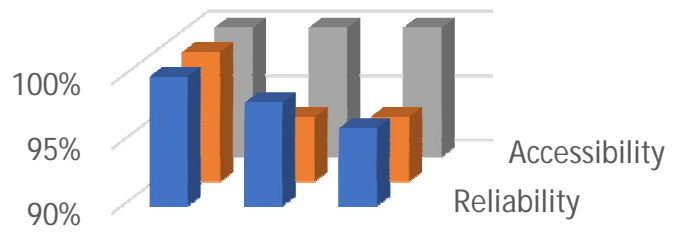

Aug Sep Oct

- Reliability $\square$ Availability $\square$ Accessibility

Figure 11: Result of proposed system

\section{ACKNOWLEDGEMENT}

The authors wish to thank Research and DevelopmentInstitute of Phanakhon Rajabhat University for fully support this work.

\section{REFERENCES}

1. Arduino Uno, "The Arduino Uno Website [Online]", history, http://arduino.cc/en/Main/arduinoBoardUno 2020

2. EAS, "Electronic Article Surveillance System (EAS) [Online]" history, https://en.wikipedia.org/wiki/Electronic_article_surveill ance 2012

3. Herzer, G., "Magnetic materials for electronic article surveillance", Journal ofMagnetism and Magnetic Materials, 254-255, p598-602, 2003.

4. Santucci PA, Haw J, Trohman RG, Pinski SL. "Interference with an implantable defibrillator by an electronic antitheft-surveillance device". $N$ Engl J Med. 1998;339:1371-1374

5. Esp32., "ArduinoInfo", The History of ESP32 http://arduinoinfo.mywikis.net/w/index.php?title=Esp32 \&oldid=122053. 2015

6. Shi, W., et al.: "Edge computing: vision and challenges". IEEE. Int. Things J. 3(5), 637-646 2016.

7. Espressif Systems, "ESP32 Datasheet", Advanced setting.

https://www.espressif.com/sites/default/files/documentat ion/esp32_datasheet_en.pdf Accessed 11 June 2019

8. Vermesan $\mathrm{O}$ and Friess P, "Internet of Things - From Research and Innovation to Market Deployment “, Denmark: River Publishers

9. Digital camera, "History and background", Digital camera https://www.cnet.com/news/photos-the-history-of-the-di gital-camera/ 2019 
Surasee Prahmkaew, International Journal of Emerging Trends in Engineering Research, 9(4), April 2021, 485 - 490

10. Arduino, "History and how to", Setting https://en.wikipedia.org/wiki/Arduino 2020

11. Line, "Line application", why popular, https://www.thailandredcat.com/the-most-popular-messe nger-apps-in-thailand 2020

12. Department of Defend United States of America, Military Handbook Reliability Prediction of Electronic Equipment (MIL-HDBK-338B), December 1991

13. Department of Defend United States of America, Military Handbook Reliability Prediction of Electronic Equipment (MIL-HDBK-217F), December 1991

14. Department of Defend United States of America, DoD Guide for Achieving Reliability, Availability, And Maintainability, August 2005 